\title{
«ПАВЛОВСКАЯ» СЕССИЯ ГЛАЗАМИ ПСИХОЛОГОВ (К 70-ЛЕТИЮ ПРОВЕДЕНИЯ)
}

\author{
А.Л. Журавлёв \\ Институт психологии РАН \\ Н.Ю. Стоюхина \\ Нижегородский государственный университет им. Н.И. Лобачевского
}

\begin{abstract}
Аннотация: В данной статье анализируются историко-психологические источники, в которых освещается большое по значимости событие для отечественной науки, в целом, и психологии, в частности, - объединенная сессия АН СССР и АМН СССР (1950 г.), посвященная проблемам физиологического учения академика И.П. Павлова.

Ключевые слова: история психологии, история науки, физиология, «павловская» сессия, объединенная сессия АН СССР и АМН СССР, павловское учение, Б.М. Теплов, С.Л. Рубинштейн, В.В. Колбановский, А.Р. Лурия
\end{abstract}

\section{THE «PAVLOVIAN» SESSION FOR 70 YEARS: FROM THE EYES OF PSYCHOLOGISTS}

\author{
A.L. Zhuravlev \\ Institute of Psychology RAS \\ N.Yu. Stoyukhina \\ Lobachevsky State University of Nizhni Novgorod
}

Abstract: This article analyzes the historical and psychological sources, which highlight an important event for psychology - the joint session of the USSR Academy of Sciences and the USSR Academy of Medical Sciences (1950), dedicated to the problems of the physiological doctrine by academician I.P. Pavlov.

Keywords: history of psychology, history of science, physiology, «Pavlovian» session, joint session of the USSR Academy of Sciences and the USSR Academy of Medical Sciences, Pavlov's doctrine, B.M. Teplov, S.L. Rubinstein, V.V. Kolbanovsky, A.R. Luria

В 2020 г. исполнилось 70 лет значимому событию в истории российской науки - с 28 июня по 4 июля 1950 г. прошла объединенная сессия АН СССР и АМН СССР, посвященная проблемам физиологического учения академика И.П. Павлова. Несмотря на неоднозначные оценки, какими сопровождалось это научное мероприятие за прошедшие десятилетия, мы не можем пройти мимо юбилея этого события.

Начало описываемым мероприятиям задает расширенное заседание Всесоюзной академии сельскохозяйственных наук имени В.И. Ленина (ВАСХНИЛ), состоявшееся 31 июня - 7 августа 1948 г. и вошедшее в историю российской на- 
уки как противостояние «мичуринской агробиологии» и классической генетики; «именно в ней разгром, учиненный Сталиным при помощи Лысенко и его подручных был наиболее зримым, и неслучайно поэтому он наиболее исследован. Другие кампании носили менее радикальный характер, были менее масштабны или привели к менее драматичным последствиям» (Добренко, 2020: 578). После сессии ВАСХНИЛ прошли «павловская» сессия и сессия по «квантовой химии (июнь 1951 г.), тщательно готовилась идеологическая дискуссия о фундаментальных физических теориях XX века, которая ...должна была закончиться разгромом физики» (Добренко, 2020: 578), и только работа советских физиков в атомном проекте не дала этому случиться.

К сожалению, со стороны психологов до сих пор не последовало целостного исследования событий того времени, и это понятно, т.к. необходимо освоить огромный материал. В данной статье попробуем лишь наметить происходившее несколько десятилетий назад, руководствуясь прежде всего опубликованными источниками.

Объемный том на 738 страниц, содержащий стенографический отчет научной сессии, посвященной проблемам физиологического учения академика И.П. Павлова, - основной источник, изучив который, можно узнать об интересующем нас научном событии.

По словам ответственного секретаря Оргкомитета Э.Ш. Айрапетьянца, из более 2 тысяч заявок для участия, поступивших из разных научных учреждений и организаций, оргкомитет одобрил 480 участников и 920 гостей. Кто же были эти люди? «Помимо действительных членов и членов-корреспондентов обеих академий, участвуют физиологи, клиницисты, биологи, психологи, философы из научно-исследовательских учреждений и высших учебных заведений 56 городов Советского Союза, а также представители всех республиканских академий наук, академий сельскохозяйственных и педагогических наук» (Научная сессия, 1950: 82). Состоялось десять заседаний с 81 выступавшим из 209 записавшихся, к тому же Оргкомитет включил в отчет тексты 51 несостоявшегося выступления. И хотя среди выступивших мало психологов - Б.М. Теплов, С.Л. Рубинштейн, В.В. Колбановский, А.Р. Лурия, - содержание их докладов заслуживает отдельной публикации. Собственно, в адрес психологии и педагогики со стороны ведущих докладчиков - ярых поборников учения И.П. Павлова не прозвучало жестких обвинений, кроме, пожалуй, сказанных слов академика К.М. Быкова: «замечательная идея И.П. Павлова о второй сигнальной системе у нас в Советском Союзе крайне недостаточно разрабатывается. Здесь большая вина лежит и на Академии педагогических наук, которая в своих научно-исследовательских институтах, на своем прекрасном детском материале, как никто лучше, могла бы развить это учение И.П. Павлова» (Научная сессия, 1950: 42).

Из пространного Постановления сессии мы узнаем, что персональное порица- 
ние «заслужили» академик И.С. Бериташвили за «антипавловскую деятельность» (Научная сессия, 1950: 522), академик А.Д. Сперанский, допустивший «в своей работе ряд ошибок» (Научная сессия, 1950: 523), профессор П.К. Анохин - «не двигал вперед павловское учение и на протяжении многих лет занимался ревизией идейных основ материалистического учения И.П. Павлова о высшей нервной деятельности, принижая его значение» (Научная сессия, 1950: 524). Больше всего досталось академику Л.А. Орбели: он пошел «по неправильному пути, сбивал последователей и нанес ущерб развитию учения И.П. Павлова», «подменял взгляды И.П. Павлова своими ошибочными высказываниями», «увел научные коллективы в сторону от разработки основных задач павловского наследия и, прикрываясь формальным признанием павловского учения, на деле извратил ряд важнейших его положений» и т.д. (Научная сессия, 1950: 522-523). В заключительной части Постановления важными для психологии (она была тогда преимущественно в педагогических вузах) были рекомендации о пересмотре программы по физиологии, преподавании специального курса основ физиологии (а также патологии) высшей нервной деятельности, создании нового учебника по физиологии - для всех педагогических вузов.

Как пишет Р. Смит, «чтобы связать физиолога XIX в. Сеченова с Павловым, а Павлова - с диалектической наукой о бытии и сознании, они («партийные ораторы» - прим. Авт.) сконструировали генеалогическое древо и возвели эту связь в ранг догмы, имевшей продолжительное влияние на советские работы по истории психологии» (Смит, 2008: 331).

После объединенной сессии двух Академий 1950 г. учение И.П. Павлова обрело новую силу, многократно увеличив цитирование во всех научных и учебных текстах. Этому способствовало также издание сборника, посвященного философским вопросам павловского учения, которые имеют «близкое отношение к проблемам психологии и требуют неотложной разработки. ...авторы стремились раскрыть философское значение учения И.П. Павлова и показать, что оно служит прочной естественнонаучной основой материалистической психологии» (Учение И.П. Павлова, 1952: 3]) Частота упоминаний павловского учения повысилась даже в учебниках по психологии для средней школы (Стоюхина, 2009: 77).

На совещании по психологии (3-8 июля 1953 г.), прошедшем сразу после смерти Сталина, вопрос об оценке «павловской» сессии, естественно, не возникал - слишком близко по времени состоялись эти события; доклады были, в основном, по проблемам психофизиологии и познавательной деятельности (Тезисы докладов, 1953).

Результатом прошедшего Совещания по психологии (1-6 июля 1955 г.) стала представительная книга материалов, вышедшая в 1955 г. Во вступительной статье о состоянии научно-исследовательской работы в области психологии А.А. Смирнов задается вопросом: «Что сделано за истекшие два года по основ- 
ным разделам психологической науки?» (Материалы совещания по психологии, 1957: 4), и в части, освещающей работы по изучению материального субстрата психики, называет учение И.П. Павлова. Интересно, что из 101 представленного доклада, имя И.П. Павлова упоминается всего в 39 выступлениях, а ссылка на прошедшую пять лет назад сессию встречается только в одной (!) работе - статье Н.В. Зыковой: «После объединенной сессии АН и АМН по вопросам развития учения И.П. Павлова в исследованиях по педагогической психологии все большее место стало занимать изучение проблемы взаимодействия слова и образа в учебной деятельности школьника» (Материалы совещания по психологии, 1957: 458).

В конце 1950-х гг. советская психология обогатилась замечательным двухтомником «Психологическая наука в СССР», ставшим ценным историко-психологическим источником. Это коллективный труд 38-ми советских психологов итоги проведенных исследований за 40 лет по основным проблемам психологии. И хотя в нем по-прежнему говорилось, что «советская психология исходит из марксистско-ленинской теории отражения и своей естественнонаучной основой имеет рефлекторную теорию психического, выдвинутую Сеченовым и развитую Павловым» (Психологическая наука..., Т.1, 1959: 4), но было заявлено и о новых задачах, поставленных перед советской психологией на XXI съезде КПСС, связанных с «величественной программой развернутого строительства коммунистического общества» (Психологическая наука, Т.1, 1959: 6). Отличает эту книгу свободные упоминания работ педологов и психотехников 1920-30-х гг. - коллег авторов, внесших вклад в различные психологические отрасли, о которых старались не говорить в предыдущие годы. Самая представительная ссылка на теорию И.П. Павлова содержится в статье Б.М. Теплова «Исследование свойств нервной системы как путь к изучению индивидуально-психологических различий»: «Перед нами стоит задача не просто хранить учение И.П. Павлова о типах высшей нервной деятельности и применять его к человеку, а творчески развивать это учение, отчетливо осознавая, что является принципиальной основой того учения, в чем заключается руководящая идея И.П. Павлова <...> (Психологическая наука..., Т.2, 1959: 10). П.А. Шеварев, предваряя статью об исследованиях по психологии восприятия, писал о «крутом переломе» в этой области, совершившемся после Павловской сессии двух академий (Психологическая наука..., Т.1, 1959: 114). Так же интересно, что в статье М.В. Соколова «Работы советских психологов по истории психологии» приводится список литературы из 455 источников, в названии только трех из них упоминается имя И.П. Павлова (Психологическая наука..., Т.2, 1959: 596-654).

В мае 1962 г. в Москве состоялось Всесоюзное совещание по философским вопросам физиологии высшей нервной деятельности и психологии, созванное Академией наук СССР, Академией медицинских наук СССР, Академией педагогических наук РСФСР и Министерствами высшего и среднего специального 
образования СССР и РСФСР с целью «дальнейшего повышения качества теоретических исследований в области физиологии и психологии и в усилении борьбы против буржуазной идеологии» (Философские вопросы..., 1963: 3). На совещании выступали философы, физиологи, психологи, педагоги, представители медицинской науки и сотрудники других отраслей науки. Вероятно, наступило время для подведения научных и исторических итогов, потому что, с одной стороны, «совещание прошло под знаком укрепления позиций диалектического материализма и отметило особое значение павловского учения о высшей нервной деятельности. Участники его особо подчеркнули задачу дальнейшего творческого развития этого учения на основе новейших достижений нейрофизиологии и кибернетики» (Философские вопросы..., 1963: 4).

С другой стороны, совещание признало: «культ личности Сталина отрицательно сказался и на ходе и результатах работы Объединенной сессии двух академий. Он сковывал творческую инициативу ученых и порождал догматизм, исказив идею научной критики, подменив товарищеский, свободный обмен мнениями декретированием теоретических положений и выводов, наклеиванием разного рода ярлыков на инакомыслящих» (Философские вопросы..., 1963: 757). Как заметил М.Г. Ярошевский, «совещание 1962 г. оказалось половинчатым, как и все разоблачения сталинщины в период хрущевской «оттепели». Его участники сказали лишь полуправду - де, невзирая на некоторые ошибки, сессия двух академий все же сыграла положительную роль» (Ярошевский, 1991: 29).

В 1970-х гг. заметным явлением стал выход двух важных изданий - «Философские проблемы в советской психологии» Е.А. Будиловой (1972) и «Развитие и современное состояние психологической науки в СССР» А.А. Смирнова (1975), в которых повторилась оценка «павловской» сессии, высказанная на Всесоюзном совещании по философским вопросам физиологии ВНД и психологии 1962 г. Подчеркнув «сложность и противоречивость обстановки» в 1950 г., павловское учение признавалось для психологии важным; «...психологи критически отнеслись к ошибочным положениям о взаимоотношении психологии и физиологии высшей нервной деятельности <..>. Психологи выступили против попыток заменить их науку физиологией высшей нервной деятельности; они решительно отстаивали ее самостоятельность, обосновывали ее предмет и доказывали объективность психологических методов» (Будилова, 2009: 163). А.А. Смирнов отметил преодоление ошибочного понимания взаимоотношения психологии и физиологии именно на Совещании по философским вопросам физиологии 1962 г. (Смирнов, 1975: 216). И заключительным событием 1970-х гг., знаменующим главенство естественно-научного подхода в психологии, стала коллективная монография, «посвященная естественнонаучным основам психологии, включающим данные морфологии и физиологии мозга и достижения наук, лежащих на стыке естественнонаучного и психологического познания: нейропсихологии и 
психофизиологии» (Естественнонаучные основы..., 1978: 5). А.Р. Лурия писал: «И.П. Павлов не отрицал психологию как науку о субъективном мире человека, который представлялся ему «первой реальностью» <...> среди некоторых физиологов, относивших себя даже к последователям И.П. Павлова, возникла тенденция заменить учением об условных рефлексах всю психологию человека <..> В итоге все высшие психические функции ...фактически остались за пределами физиологического анализа» (Естественнонаучные основы..., 1978: 13).

Сейчас во многом забыто и важное событие октября 1987 г. - «круглый стол» в Институте истории естествознания и техники АН СССР с участием 35 физиологов, философов, историков науки, психологов, «давших однозначную оценку «павловской сессии» как принесшей неисчислимые беды не только физиологии, но и многим другим направлениям, в том числе самому павловскому учению о высшей нервной деятельности» (Ярошевский, 1991: 31). В этих материалах сформулированы, пожалуй, впервые четкие оценки последствий, которые советская наука с большим трудом преодолевала.

С конца 1980-начала 1990-х гг. была предпринята новая попытка переосмысления «павловской сессии», явившаяся очень крупным и значимым историческим событием, особенно по своим последствиям. Некоторые историки сравнили послевоенные научные сессии с «горным кряжем» (Петрюк, Петрюк, 2016). На новом историческом этапе научное сообщество, получая ранее неизвестные документы, вновь оценивало прошлое, но, как нам кажется, дальше эмоциональных оценок продвинуться в этом анализе пока не получается.

Можно отметить недостаточное желание разобраться в деталях историко-психологической составляющей «павловской» сессии, ее последствий, ибо из текста в текст повторяется схема-объяснение: эпигоны Павлова хотели ликвидировать психологию как самостоятельную науку, заменив ее физиологией ВНД; в результате проведенной сессии психология должна была утвердиться на твердом естественнонаучном фундаменте - рефлекторной продукции высшей нервной деятельности. Во-первых, хотелось бы прочитать выступления докладчиков, говоривших о своих намерениях относительно психологии. Во-вторых, как справедливо заметил Л.Р. Грэхэм, авторы обычно уклоняются от ответа на вопрос о том, в какой степени ответственность за события 50-х годов несет Сталин, а в какой - система, господствовавшая в то время в советском обществе и позволявшая ему осуществлять подобное давление в том числе и на науку» (Грэхэм, 1991: 180).

В послеперестроечное время, в условиях открытости, опираясь на документы, мы узнавали новые данные буквально по крупицам и, откровенно говоря, не сильно продвинулись в понимании «павловской» сессии и того исторического периода, в целом. Это, бесспорно, еще предстоит сделать.

В 1990 г. «Психологический журнал» сделал важный шаг к ознакомлению 
психологического сообщества с историей «павловской» сессии, опубликовав на своих страницах выступления Б.М. Теплова, С.Л. Рубинштейна, В.В. Колбановского и А.Р. Лурия на Объединенной научной сессии АН СССР и АМН СССР, предварив их исторической справкой, объясняющей тон этих выступлений: «участники сессии не могли хотя бы в минимальной степени не выполнить жестких стандартных требований, которые предъявлялись в «сталинскую эпоху» ко всем выступавшим с трибуны и в печати. Это в первую очередь обязательные ссылки на Сталина, безоговорочное одобрение директивных указаний, критика коллег и особенно самокритика..., резкая критика западной науки и т.д.» (К 40-летию «павловской» сессии..., 1990: 141). В то время такой была «правильная» публикация, но сейчас она требует более широкого освещения исторического контекста.

Историки психологии из Института психологии РАН, в целом согласившись с оценками павловской сессии, данными Е.А. Будиловой, А.А. Смирновым, Е.В. Шороховой, отметили последовательность важных для психологии исторических событий: Совещание, посвященное перестройке психологии в соответствии с павловским учением, где обсуждались принципиально важные методологические положения (30 июня - 5 июля 1952 г.); дискуссия на тему «Некоторые вопросы советской психологии», проведенная Президиумом Академии наук Грузинской ССР с обсуждением соответствия концепции Д.Н. Узнадзе об установке павловскому учению (8-11 апреля 1952 г.); дискуссия на тему «Проблема ощущения в свете марксистско-ленинской теории познания», организованная ректоратом ЛГУ (16-19 февраля 1953 г.) (Психологическая наука...., 1997: 129). Наверняка, подобные дискуссии, совещания и т.п. проводились практически в каждом вузе страны, подтверждением тому служит, например, исследование влияния павловской сессии на научную и педагогическую деятельность вузовской интеллигенции на материалах г. Молотова (Перми) (Малыгина, 2010). Вызывает большой интерес также интеллектуальная биография Н.А. Бернштейна (Сироткина, 2018), в которой несколько интересных страниц отводится роли павловской сессии в жизни ученого.

Современным историкам психологии необходимо выполнить детальный анализ происшедшего с психологией на «павловской» сессии: критика научного содержания, претензии к конкретным ученым, их динамика и т.д. Результаты такого исследования могут иметь как научно-психологическое, так и социальное значение. Только недостаточно точным воспроизведением анализируемого материала можно объяснить публикацию следующего текста: «известная своими не совсем адекватными решениями «павловская сессия» 1952 года, организаторы которой К.М. Быков и А.Г. Иванов-Смоленский требовали «заменить психологию физиологией...» (Помогайбин, 2013: 315). Очевидно, у автора наложились два научных события: Научная сессия, посвященная проблемам физиологическо- 
го учения академика И.П. Павлова 1950 г. и совещание по вопросам психологии 1952 г. К тому же, можно согласиться с А.Н. Ждан в том, что «освобожденное от искажений и идеологических деформаций учение И.П. Павлова продолжает сохранять свое значение для понимания поведения и его причинного объяснения» (Ждан, 2002: 273). При этом важно и нужно освободить от мифов и искажений взаимодействие физиологии и психологии 1940-1950-х гг.

Тщательный анализ идеологических кампаний в науке, ставших средством воздействия на ученых, позволяет заключить, что они отрицательно повлияли на объективное состояние науки, на моральную атмосферу в научной среде - было ограничено научное творчество ученых, более того, некоторые из них были уволены. Надолго укрепились идеологические положения, не относящиеся к науке: партийность, «марксистскость», «практика - основа науки», провозглашение основоположника, обязательная самокритика (подробнее см.: Кременцов, 1994).

\section{СПИСОК ЛИТЕРАТУРЫ}

Будилова Е.А. (2009) Труды по истории психологии. М.: Наука. 504 с.

Грэхэм Л.Р. (1991) Естествознание, философия и науки о человеческом поведении в Советском Союзе. М.: Политиздат. 480 c.

Добренко Е. (2020) Поздний сталинизм: эстетика политики. Т.1. М.: Новое литературное обозрение. 712 c.

Естественнонаучные основы психологии (1978) М.: Педагогика. 368 с.

Ждан А.Н. (2002) История психологии. От античности к современности: Учебник для вузов. М.: Академический проект; Екатеринбург: Деловая книга. 528 с.

К 40-летию «Павловской» сессии... двух академий (1990) // Психологический журнал. Т. 11. № 4. С. 140-152; Т. 11. № 5. С. 123-133.

Кременцов Н.Л. (1994) Равнение на ВАСХНИЛ // Репрессированная наука. Выпуск II / Ред. М.Г. Ярошевский. СПб.: Наука. 319 с. С. 83-96.

Малыгина О.А. (2010) О влиянии павловской сессии на исследовательскую и педагогическую деятельность вузовской интеллигенции г. Молотова // Известия Уральского государственного университета. Серия 1: Проблемы образования, науки и культуры. № 6-2. С. 308-313.

Материалы совещания по психологии (1-6 июля 1955 г.) (1957). М.: Изд-во АПН РСФСР. $731 \mathrm{c}$.

Научная сессия, посвященная проблемам физиологического учения академика И.П. Павлова 28 июня-4 июля 1950 г. (1950) Стенографический отчет. М.: Издательство АН СССР. 734 с.

Петрюк П.Т., Петрюк, А.П. (2016) Некоторые рассуждения о 65-летии Павловской сессии // Вестник Ассоциации психиатров Украины. № 1-2. С. 129-137.

Помогайбин В.Н. (2013) История психологии: эволюция основ. М.: ОЛМА Медиа Групп. 520 с. 
Психологическая наука в России XX столетия: проблемы теории и истории. (1997) Под ред. А.В. Брушлинского. М.: Ин-т психологии РАН. 576 с.

Сироткина И. Мир как живое движение. Интеллектуальная биография Николая Бернштейна (2018) М: Когито-Центр. 252 с.

Смирнов А.А. (1975) Развитие и современное состояние психологической науки в СССР. М.: Педагогика. 352 с.

Смит Р. (2008) История психологии: учеб. пособ. для студ. высш. учеб. заведений. М.: Издательский центр «Академия». 416 с.

Стоюхина Н.Ю. (2009) Взаимодействие и противостояние психологии и физиологии в школьных учебниках в СССР в 1950 гг. // Методология и история психологии. Т. 4. Вып. 2. С. 76-86.

Тезисы докладов на совещании по психологии (1953) М.: АПН РСФСР. 68 с.

Учение И.П. Павлова и философские вопросы психологии (1952) М.: AH CCCP. 475 c.

Философские вопросы физиологии высшей нервной деятельности и психологии (1963) М.: АН СССР. 771 с.

Ярошевский М.Г. (1991) Сталинизм и судьбы советской науки // Репрессированная наука. Л.: Наука. С. 6-33.

Журавлёв Анатолий Лактионович - академик РАН, профессор, научный руководитель ФГБУН Институт психологии РАН. Адрес: 129366, Россия, г. Москва, ул. Ярославская, 13, корп. 1. Тел.: +7(985) 220-93-46. Эл. адрес: alzhuravlev2018@yandex.ru

Zhuravlev Anatoly Laktionovich - Academician of the Russian Academy of Sciences, Professor, Scientific Director of the Institute of Psychology RAS. Postal address: 129366, Russia, Moscow, st. Yaroslavskaya, 13-1. Tel.: +7 (985) 220-93-46. Email: alzhuravlev2018@yandex.ru

Стоюхина Наталья Юрьевна - кандидат психологических наук, доцент, доцент кафедры психологии управления Нижегородского государственного университета им. Н.И. Лобачевского. Адрес: 603000, Россия, г. Нижний Новгород, Университетский пер., д. 7. Тел.: +7(910) 382-71-46. Эл. адрес: natast0@rambler.ru

Stoyukhina Nataliya Yurievna - Candidate of Psychology, Associate Professor, Associate Professor, Department of Administration Psychology, Lobachevsky State University of Nizhny Novgorod. Postal address: 7, Universitetsky Lane, Nizhny Novgorod, Russian Federation, 603000. Tel.: +7 (910) 382-71-46. E-mail: natast0@rambler.ru

\section{Для цитирования:}

Журавлёв А.Л., Стоюхина Н.Ю. «Павловская» сессия глазами психологов (к 70-летию проведения) // Научные труды Московского гуманитарного университета. 2020. №5. C. 4-12. DOI: https://www.doi.org/10.17805/trudy.2020.5.1 